\title{
Modelling of propeller shaft dynamics at pulse load
}

\author{
Andrzej Grządziela, Assoc. Prof. \\ Polish Naval University
}

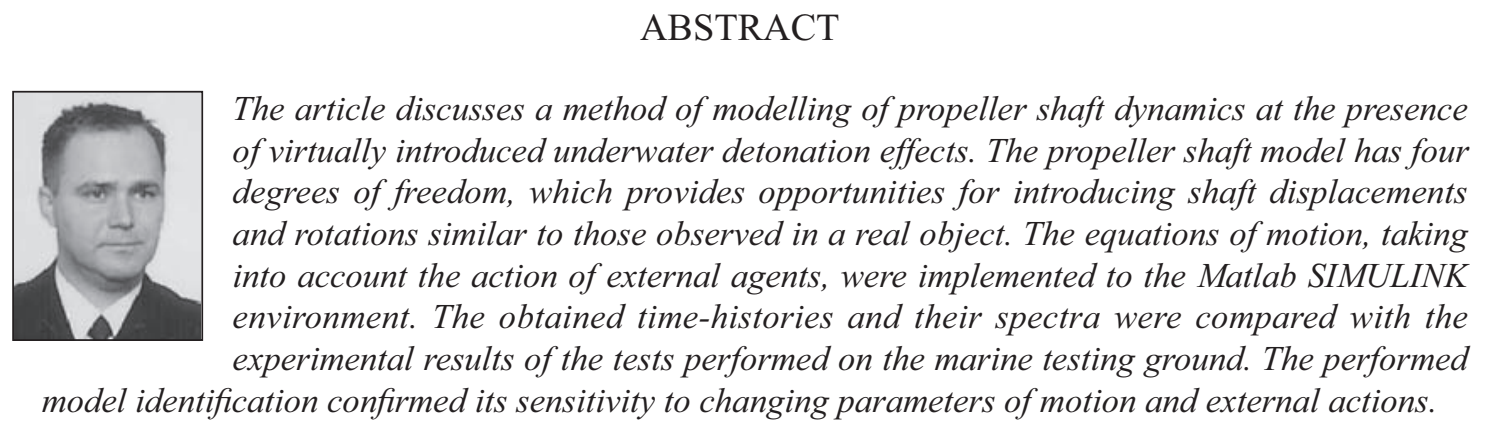

Keywords :

\section{INTRODUCTION}

Modelling of technical machines and devices is nowadays done in the form of mathematical and physical models of canonical equations, or virtual $3 \mathrm{D}$ tools. Both methods return comparable results, and selecting one of them is determined by an individual approach to the problem, or past experience and habits of a research worker. A basic goal of modelling for diagnostic purposes is to be able to predict failure symptoms, both of primary and secondary nature. The application of static or dynamic loads makes it possible to shorten considerably the time and reduce significantly the cost of the investigations. An important property of the modelling is the ability to introduce complex virtual damages, which in practice either occur rarely, or their occurrence leads to rapid destruction of the machine or group of machines. The modelling aims at finding a group of sensitive symptoms, which uniquely interpret changes of technical state of the machine. The created set of symptoms, tested on a real object, makes a good basis for fast and easy implementation of the vibration based diagnostic system.

The article analyses modes of free vibration of the propeller shaft in the ANSYS environment, and the model of action of underwater detonation, understood as the right-hand side of the second-type Lagrange equation. The ability to introduce virtual damages, such as shaft line axis misalignment, for instance, makes it possible to obtain a sensitive, diagnostic oriented model of the propeller shaft. The following actions were introduced to the proposed dynamic model [2]:

$>$ main engine driving torque

$>$ screw propeller anti-torque

axial thrust force the action resulting from changes in relative positions of load-carrying bearings and thrust bearings in the shaft line

$>$ the action of the hydrodynamic pressure generated by an underwater detonation.

\section{D MODELLING}

The analysis of the propeller shaft dynamics bases on a 3D model worked out in SOLID Works environment and analysed in the ANSYS environment - see Fig. 1. The performed analyses aimed at obtaining the information on free vibration modes of the shaft, with further identification of possible threats during its operation. The results of the analyses of four initial free vibration modes are collected in Tab. 1. These results confirm an opinion that during the operation of a real propulsion system the propeller shaft, working within the range of $n_{P S}=150 \div 900$ $\mathrm{rev} / \mathrm{min}$, is subject to the appearance of resonances.

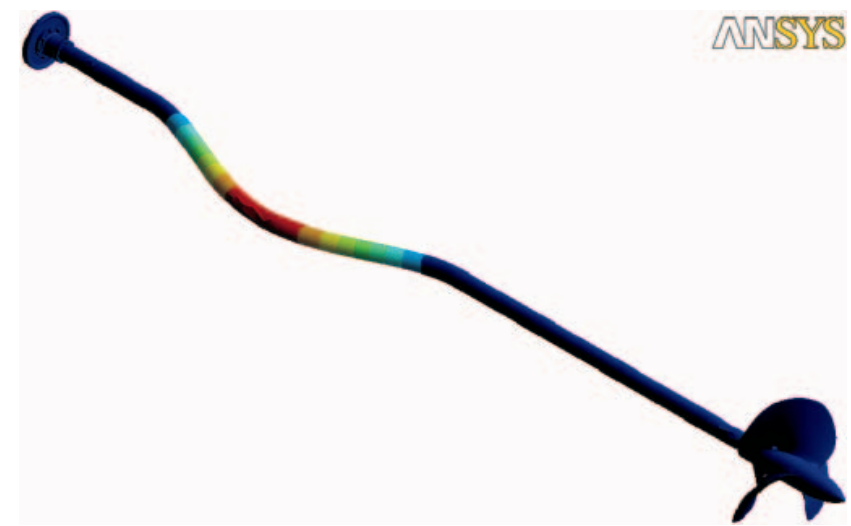

Fig. 1. Sample free vibration mode observed in the analysed propeller shaft 
Tab. 1. Analysis of four initial free vibration modes of the shaft

\begin{tabular}{|c|c|c|c|}
\hline $\begin{array}{c}\text { Mode } \\
\text { (vibration } \\
\text { mode } \\
\text { number) }\end{array}$ & $\begin{array}{c}\text { Analysed degree of } \\
\text { freedom }\end{array}$ & $\begin{array}{c}\text { Frequency } \\
\text { [Hz] }\end{array}$ & $\begin{array}{c}\text { Shaft } \\
\text { revolutions } \\
\text { [rev/min] }\end{array}$ \\
\hline 1 & $\begin{array}{c}\text { Axial. torsional - free } \\
\text { Axial - fixed }\end{array}$ & 7.8386 & 470.30 \\
\hline 2 & $\begin{array}{c}\text { Axial. torsional - free } \\
\text { Axial - fixed }\end{array}$ & 7.8529 & 471.17 \\
\hline 3 & $\begin{array}{c}\text { Axial. torsional - free } \\
\text { Axial - fixed }\end{array}$ & 23.961 & 1437.6 \\
\hline 4 & $\begin{array}{c}\text { Axial. torsional - free } \\
\text { Axial - fixed }\end{array}$ & 24.023 & 1441.4 \\
\hline
\end{tabular}

\section{DYNAMIC MODEL OF THE SHAFT LINE}

In the propeller shaft model the driving torque of the internal combustion piston engine is transmitted via the reduction gear to the constant-pitch propeller. The model meets the following requirements:

$\star$ makes it possible to introduce the action of external agents

$\star$ reveals sensitivity to changing parameters of propeller shaft motion

$\star$ reveals sensitivity to propeller shaft axis misalignment

* reveals no sensitivity of the coaxiality symptom to disturbances coming from the environment

$\star$ preserves the compliance of the spectral structure in the frequency domain with the results of measurements done on a real object.
The propeller shaft model was an object of simulation tests to check its sensitivity to the action of external agents and compliance with the behaviour of the object in the conditions of the simulated environmental action [5]. The proposed model is nonlinear, and an attempt to describe it by linearisation of actions is unacceptable as it may lead to incorrect conclusions resulting from possible superposition of the effects observed in linear systems [3]. Since in the equations of motion the time is represented explicitly, this system is non-autonomous. A scheme of the reactions on supports at the presence of the external actions is given in Fig. 2.

The kinetic energy of the presented system was written as:

$$
\mathrm{E}_{\mathrm{k}}=\frac{1}{2} \mathrm{I}_{\mathrm{N}} \dot{\varphi}_{\mathrm{N}}^{2}+\frac{1}{2} \mathrm{I}_{\mathrm{SR}} \dot{\varphi}_{\mathrm{SR}}^{2}+\frac{1}{2} \mathrm{~m}_{\mathrm{I}}\left(\dot{\mathrm{v}}_{\mathrm{I}}^{2}+\dot{\mathrm{h}}_{\mathrm{I}}^{2}\right)+
$$

$+\frac{1}{2} \mathrm{~m}_{\mathrm{II}}\left(\dot{\mathrm{V}}_{\mathrm{II}}^{2}+\dot{\mathrm{h}}_{\mathrm{II}}^{2}\right)+\frac{1}{2} \mathrm{~m}_{\mathrm{SR}}\left(\dot{\mathrm{v}}_{\mathrm{SR}}^{2}+\dot{\mathrm{h}}_{\mathrm{SR}}^{2}\right)+\frac{1}{2} \mathrm{~m}_{\mathrm{N}}\left(\dot{\mathrm{V}}_{\mathrm{N}}^{2}+\dot{\mathrm{h}}_{\mathrm{N}}^{2}\right)$

Then, the potential energy of the system was written as:

$\mathrm{E}_{\mathrm{p}}=\frac{1}{2} \mathrm{k}_{\mathrm{NS}} \varphi_{\mathrm{N}}^{2}+\frac{1}{2} \mathrm{k}_{\mathrm{wS}}\left(\varphi_{\mathrm{SR}}-\varphi_{\mathrm{N}}\right)^{2}+\frac{1}{2} \mathrm{k}_{\mathrm{Ig}}\left(\mathrm{h}_{\mathrm{I}}^{2}+\mathrm{v}_{\mathrm{I}}^{2}\right)+$

$+\frac{1}{2} \mathrm{k}_{\text {II }}\left(\mathrm{h}_{\mathrm{II}}^{2}+\mathrm{v}_{\mathrm{II}}^{2}\right)+\frac{1}{2} \mathrm{k}_{\mathrm{IIg}}\left(\mathrm{h}_{\mathrm{III}}^{2}+\mathrm{v}_{\mathrm{III}}^{2}\right)+\frac{1}{2} \mathrm{k}_{\text {IVg }}\left(\mathrm{h}_{\mathrm{SR} 1}^{2}+\mathrm{v}_{\mathrm{SR} 1}^{2}\right)$

And, finally, the dispersed energy was written as:

$$
\begin{gathered}
\mathrm{E}_{\mathrm{R}}=\frac{1}{2} \mathrm{c}_{\mathrm{ws}}\left(\dot{\varphi}_{\mathrm{SR}}-\dot{\varphi}_{\mathrm{N}}\right)^{2}+\frac{1}{2} \mathrm{c}_{\mathrm{Ts}} \dot{\varphi}_{\mathrm{SR}}^{2}+\frac{1}{2} \mathrm{c}_{\mathrm{Ig}}\left(\dot{\mathrm{h}}_{\mathrm{I}}^{2}+\dot{\mathrm{v}}_{\mathrm{I}}^{2}\right)+ \\
+\frac{1}{2} \mathrm{c}_{\mathrm{IIg}}\left(\dot{\mathrm{h}}_{\mathrm{II}}^{2}+\dot{\mathrm{v}}_{\mathrm{II}}^{2}\right)+\frac{1}{2} \mathrm{c}_{\mathrm{III}}\left(\dot{\mathrm{h}}_{\mathrm{III}}^{2}+\dot{\mathrm{v}}_{\mathrm{III}}^{2}\right)+\frac{1}{2} \mathrm{c}_{\mathrm{IVg}}\left(\dot{\mathrm{h}}_{\mathrm{SRI}}^{2}+\dot{\mathrm{v}}_{\mathrm{SRl}}^{2}\right)
\end{gathered}
$$

The external actions of the drive, understood as the driving torque and the required propeller torque, were given as:

$$
\begin{aligned}
& \text { - - - - - - - - - - - - - - - } \\
& \text { b) } \\
& \begin{aligned}
\mathrm{h}_{\mathrm{SR} 1} & =\mathrm{h}_{\mathrm{SR}}-\mathrm{e} \cdot \cos \varphi_{\mathrm{SR}} \\
\mathrm{v}_{\mathrm{SR} 1} & =\mathrm{v}_{\mathrm{SR}}-\mathrm{e} \cdot \cos \varphi_{\mathrm{SR}} \\
\mathrm{r}_{\mathrm{SR}} & =\sqrt{\mathrm{h}_{\mathrm{SR} 1}^{2}+\mathrm{v}_{\mathrm{SR} 1}^{2}}
\end{aligned}
\end{aligned}
$$
$\mathrm{I}_{\mathrm{N}} ; \mathrm{m}_{\mathrm{N}}$
$\mathrm{I}_{\mathrm{SR}} ; \mathrm{m}_{\mathrm{SR}}$
$\mathrm{M}_{\mathrm{N}} ; \mathrm{M}_{\mathrm{SR}}$
$\mathrm{m}_{\mathrm{I}} ; \mathrm{m}_{\mathrm{II}} ; \mathrm{m}_{\mathrm{III}}$
$\mathrm{k}_{\mathrm{Ns}} \quad-$ torsional stiffness of the drive
$r_{i 1} ; r_{i 2} ; r_{i 3} ; r_{i 4} ; \quad-$ transverse stiffness coefficients of shaft elements between successive supports
$\mathrm{c}_{\mathrm{Ig}} ; \mathrm{c}_{\mathrm{IIg}} ; \mathrm{c}_{\mathrm{IIIg}} ; \mathrm{c}_{\mathrm{IVg}}-$ transverse dampings of shaft elements between successive supports$$
\mathrm{k}_{\mathrm{ws}} ; \mathrm{c}_{\mathrm{ws}}
$$$$
\varphi_{\mathrm{N}} ; \varphi_{\mathrm{SR}}
$$$$
\mathrm{h}_{\mathrm{SR}} ; \mathrm{v}_{\mathrm{SR}}
$$$$
\mathrm{h}_{\mathrm{SR} 1} ; \mathrm{v}_{\mathrm{SR} 1}
$$$$
\mathrm{h}_{\mathrm{N}} ; \mathrm{h}_{\mathrm{I}} ; \mathrm{h}_{\mathrm{II}} ; \mathrm{v}_{\mathrm{N}} ; \mathrm{v}_{\mathrm{I}} ; \mathrm{v}_{\mathrm{II}}-\text { horizontal and vertical coordinates for }
$$$$
\mathrm{c}_{\mathrm{Tg}} ; \mathrm{c}_{\mathrm{Ts}}
$$
- shaft stiffness and torsional damping
- rotation angles of the drive and the screw, respectively
- horizontal and vertical coordinate of the gravity centre $\mathrm{S}_{\mathrm{c}}$ (taking into account shaft deflection)
- horizontal and vertical coordinate of the rotation centre $\mathrm{O}_{1}$ masses $\mathrm{m}_{\mathrm{N}} ; \mathrm{m}_{\mathrm{I}} ; \mathrm{m}_{\mathrm{II}}$
- water damping resistance: transverse (neglected) and torsional. 


$$
\mathrm{Q}=\mathrm{M}_{\mathrm{N}}-\mathrm{M}_{\mathrm{sr}}
$$

Calculating the stiffness $\mathrm{k}$ requires solving the statically undeterminable system, which was done using the method of impact coefficients $\alpha_{i j}$ (and coefficients $r_{i j}=f\left(\alpha_{i j}\right)$ depending on them). In the first step, making use of the equation of three moments and the Wierieszczagin method, the impact coefficients were determined in a general form:

$$
\begin{gathered}
\alpha_{\mathrm{k}-1, \mathrm{k}}=\alpha_{\mathrm{k}, \mathrm{k}-1}=\frac{1_{\mathrm{k}}}{6 \mathrm{EJ}_{\mathrm{k}}} \\
\alpha_{\mathrm{k}, \mathrm{k}}=\frac{1}{3}\left(\frac{1_{\mathrm{k}}}{\mathrm{EJ}_{\mathrm{k}}}+\frac{1_{\mathrm{k}+1}}{\mathrm{EJ}_{\mathrm{k}+1}}\right) \\
\alpha_{\mathrm{k}+1, \mathrm{k}}=\alpha_{\mathrm{k}, \mathrm{k}+1}=\frac{1_{\mathrm{k}+1}}{6 \mathrm{EJ}_{\mathrm{k}+1}}
\end{gathered}
$$

Then, by rearranging the general formula (in the matrix form) $\mathrm{y}_{\mathrm{i}}=\alpha_{\mathrm{ij}} \mathrm{S}_{\mathrm{i}}$ to the form $\mathrm{S}_{\mathrm{j}}=\mathrm{r}_{\mathrm{ij}} \mathrm{y}_{\mathrm{i}}$ the coefficient $\mathrm{r}_{\mathrm{ij}}$ was determined (taking into account that some matrix elements are equal to zero):

$$
\left[\begin{array}{l}
\mathrm{S}_{1} \\
\mathrm{~S}_{2} \\
\mathrm{~S}_{3} \\
\mathrm{~S}_{4}
\end{array}\right]=\left[\begin{array}{cccc}
\mathrm{a}_{11} & \mathrm{a}_{12} & 0 & 0 \\
\mathrm{a}_{21} & \mathrm{a}_{22} & \mathrm{a}_{23} & 0 \\
0 & \mathrm{a}_{32} & \mathrm{a}_{33} & \mathrm{a}_{34} \\
0 & 0 & \mathrm{a}_{43} & \mathrm{a}_{44}
\end{array}\right]^{-1}\left[\begin{array}{l}
\mathrm{y}_{1} \\
\mathrm{y}_{2} \\
\mathrm{y}_{3} \\
\mathrm{y}_{4}
\end{array}\right]
$$

After using the second type Lagrange equations and introducing coefficients $r_{i j}$ to these equations we arrived at Equations (9) which describe the vibrational motion of the propeller shaft. These equations were introduced to the Matlab SIMULINK environment - Fig. 3. Then, the model was complemented by the actions of virtual external agents, which can act individually or in a coupled form. The obtained simulation results refer to the following issues:

+ the analysis of propeller shaft vibrations in stationary conditions

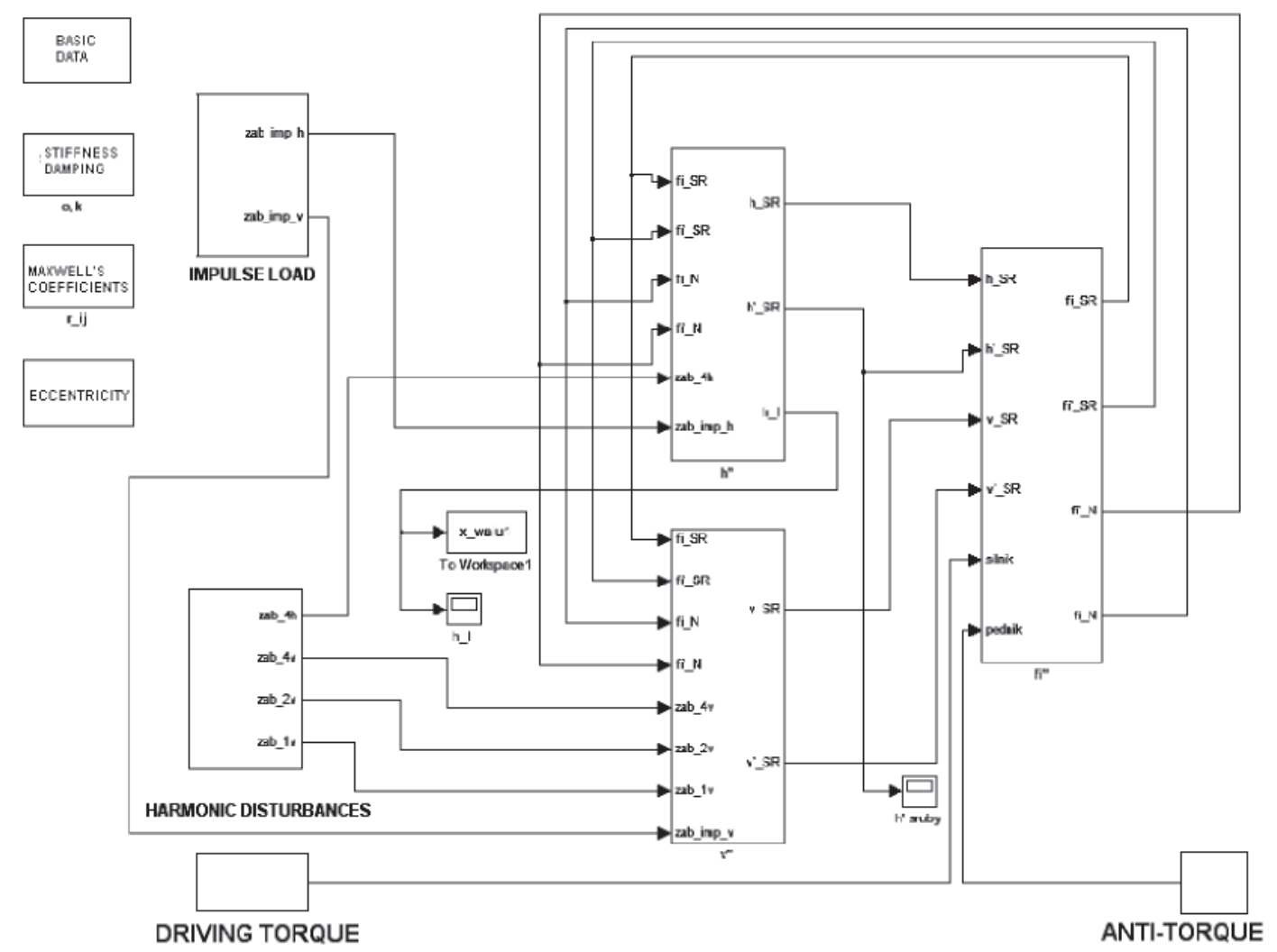

+ the analysis of the system response to individually introduced external dynamic disturbances, such as changes of parameters of coaxiality and underwater detonation pulse

+ the analysis of system response to external dynamic disturbances introduced in a coupled form, for instance for assumed changing coaxiality parameters at the presence of the underwater detonation pulse.

$\mathrm{I}_{\mathrm{N}} \ddot{\varphi}_{\mathrm{N}}+\mathrm{c}_{\mathrm{wS}}\left(\dot{\varphi}_{\mathrm{N}}-\dot{\varphi}_{\mathrm{SR}}\right)+\mathrm{k}_{\mathrm{NS}} \varphi_{\mathrm{N}}+\mathrm{k}_{\mathrm{wS}}\left(\varphi_{\mathrm{N}}-\varphi_{\mathrm{SR}}\right)=\mathrm{M}$ $\mathrm{m}_{\mathrm{I}} \ddot{\mathrm{h}}_{\mathrm{I}}+\mathrm{c}_{\mathrm{Ig}} \dot{\mathrm{h}}_{\mathrm{I}}+\mathrm{r}_{11} \mathrm{~h}_{\mathrm{I}}+\mathrm{r}_{12} \mathrm{~h}_{\mathrm{II}}+\mathrm{r}_{13} \mathrm{~h}_{\mathrm{III}}+\mathrm{r}_{14} \mathrm{~h}_{\mathrm{SR}}=0$ $\mathrm{m}_{\mathrm{I}} \ddot{\mathrm{v}}_{\mathrm{I}}+\mathrm{c}_{\mathrm{Ig}} \dot{\mathrm{v}}_{\mathrm{I}}+\mathrm{r}_{11} \mathrm{v}_{\mathrm{I}}+\mathrm{r}_{12} \mathrm{v}_{\mathrm{II}}+\mathrm{r}_{13} \mathrm{v}_{\mathrm{III}}+\mathrm{r}_{14} \mathrm{v}_{\mathrm{SR}}=0$ $\mathrm{m}_{\text {II }} \ddot{\mathrm{h}}_{\text {II }}+\mathrm{c}_{\text {IIg }} \dot{\mathrm{h}}_{\mathrm{II}}+\mathrm{r}_{21} \mathrm{~h}_{\mathrm{I}}+\mathrm{r}_{22} \mathrm{~h}_{\mathrm{II}}+\mathrm{r}_{23} \mathrm{~h}_{\text {III }}+\mathrm{r}_{24} \mathrm{~h}_{\mathrm{SR}}=0$ $\mathrm{m}_{\text {II }} \ddot{\mathrm{v}}_{\text {II }}+\mathrm{c}_{\text {IIg }} \dot{\mathrm{v}}_{\text {II }}+\mathrm{r}_{21} \mathrm{v}_{\text {I }}+\mathrm{r}_{22} \mathrm{v}_{\text {II }}+\mathrm{r}_{23} \mathrm{v}_{\text {III }}+\mathrm{r}_{24} \mathrm{v}_{\text {SR }}=0$ $\mathrm{m}_{\text {III }} \ddot{\mathrm{h}}_{\text {III }}+\mathrm{c}_{\text {IIIg }} \dot{\mathrm{h}}_{\text {III }}+\mathrm{r}_{31} \mathrm{~h}_{\mathrm{I}}+\mathrm{r}_{32} \mathrm{~h}_{\text {II }}+\mathrm{r}_{33} \mathrm{~h}_{\text {III }}+\mathrm{r}_{34} \mathrm{~h}_{\text {SR }}=0$ $\mathrm{m}_{\text {III }} \ddot{\mathrm{v}}_{\text {III }}+\mathrm{c}_{\text {IIIg }} \dot{\mathrm{v}}_{\text {III }}+\mathrm{r}_{31} \mathrm{v}_{\text {I }}+\mathrm{r}_{32} \mathrm{v}_{\text {II }}+\mathrm{r}_{33} \mathrm{v}_{\text {III }}+\mathrm{r}_{34} \mathrm{v}_{\text {SR }}=0$ $\mathrm{I}_{\mathrm{SR}} \ddot{\varphi}_{\mathrm{SR}}+\mathrm{c}_{\mathrm{ws}}\left(\dot{\varphi}_{\mathrm{SR}}-\dot{\varphi}_{\mathrm{N}}\right)+\mathrm{c}_{\mathrm{Ts}} \dot{\varphi}_{\mathrm{SR}}+\mathrm{c}_{\mathrm{IIIg}}\left(\dot{\mathrm{h}}_{\mathrm{SR}} \mathrm{e} \sin \varphi_{\mathrm{SR}}+\right.$ $\left.-\dot{\mathrm{v}}_{\mathrm{SR}} \mathrm{e} \cos \varphi_{\mathrm{SR}}+\mathrm{e}^{2} \dot{\varphi}_{\mathrm{SR}}\right)+\mathrm{k}_{\mathrm{wS}}\left(\varphi_{\mathrm{SR}}-\varphi_{\mathrm{N}}\right)+$ $+r_{44}\left(h_{S R} e \sin \varphi_{S R}-v_{S R} e \cos \varphi_{S R}\right)=M_{S R}$

$\mathrm{m}_{\mathrm{SR}} \ddot{\mathrm{h}}_{\mathrm{SR}}+\mathrm{c}_{\mathrm{IVg}}\left(\dot{\mathrm{h}}_{\mathrm{SR}}+\dot{\varphi}_{\mathrm{SR}} \mathrm{e} \sin \varphi_{\mathrm{SR}}\right)+\mathrm{r}_{41} \mathrm{~h}_{\mathrm{I}}+\mathrm{r}_{42} \mathrm{~h}_{\mathrm{II}}+\mathrm{r}_{43} \mathrm{~h}_{\mathrm{III}}+$ $+r_{44}\left(h_{\mathrm{SR}}-e \cos \varphi_{\mathrm{SR}}\right)=0$

$$
\begin{aligned}
\mathrm{m}_{\mathrm{SR}} \ddot{\mathrm{V}}_{\mathrm{SR}} & +\mathrm{c}_{\mathrm{IVg}}\left(\dot{\mathrm{V}}_{\mathrm{SR}}-\dot{\varphi}_{\mathrm{SR}} \mathrm{e} \cos \varphi_{\mathrm{SR}}\right)+\mathrm{r}_{41} \mathrm{~V}_{\mathrm{I}}+\mathrm{r}_{42} \mathrm{~V}_{\mathrm{II}}+ \\
& +\mathrm{r}_{43} \mathrm{~V}_{\mathrm{TII}}+\mathrm{r}_{44}\left(\mathrm{v}_{\mathrm{SR}}-\operatorname{esin} \varphi_{\mathrm{SR}}\right)=0
\end{aligned}
$$

The calculations performed in the Matlab SIMULINK environment aimed at iterative introduction of changes of dynamic parameters describing the operation of the propeller

Fig. 3. Starting block of the propeller shaft model in the Matlab SIMULINK environment 
shaft model in the simulated real conditions. The model components included the driving torque and anti-torque, changes in the displacement of the propeller shaft axis, and the pulse load coming from an underwater detonation. The underwater detonation model assumed the existence of three successive gas bubble pulses $[1,4]$.

Selected sample simulations of the vibration acceleration spectra recorded at point 2 at the presence of environmental action are given in Fig. 4, while Fig. 5 additionally includes the underwater detonation.

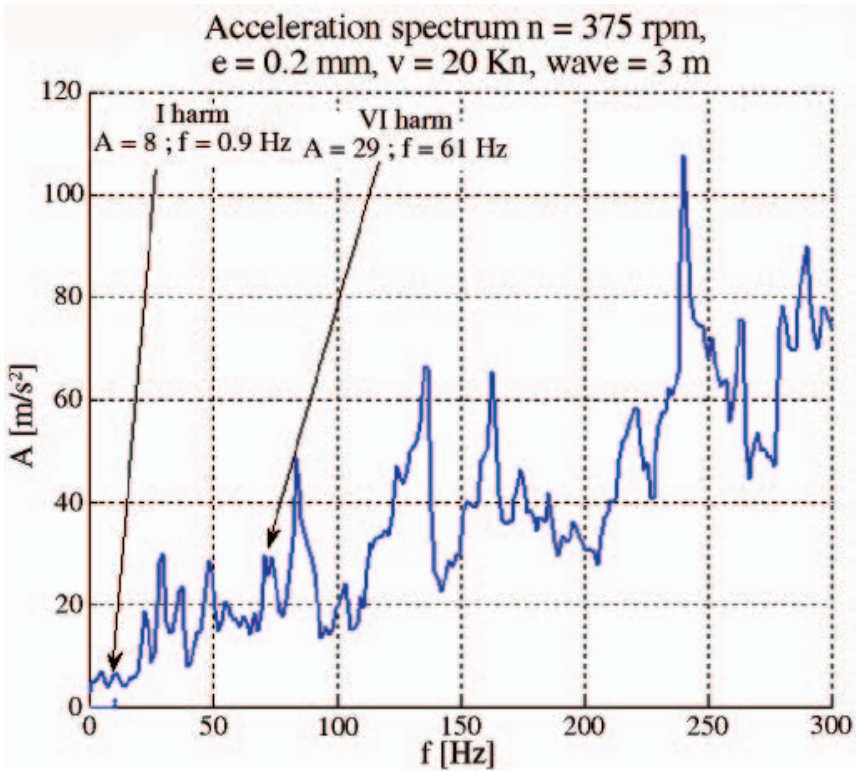

Fig. 4. Simulated transverse vibration spectrum at point 2 for $n_{P S}=375 \mathrm{rev} / \mathrm{min}, P=0.2 \mathrm{~mm}, \varangle K=0^{\circ}$ and $\varsigma=3 \mathrm{~m}$

Acceleration spectrum with impulse load, $\mathrm{n}=375 \mathrm{rpm}, \mathrm{P}=0.2 \mathrm{~mm}, \mathrm{v}=20 \mathrm{Kn}$

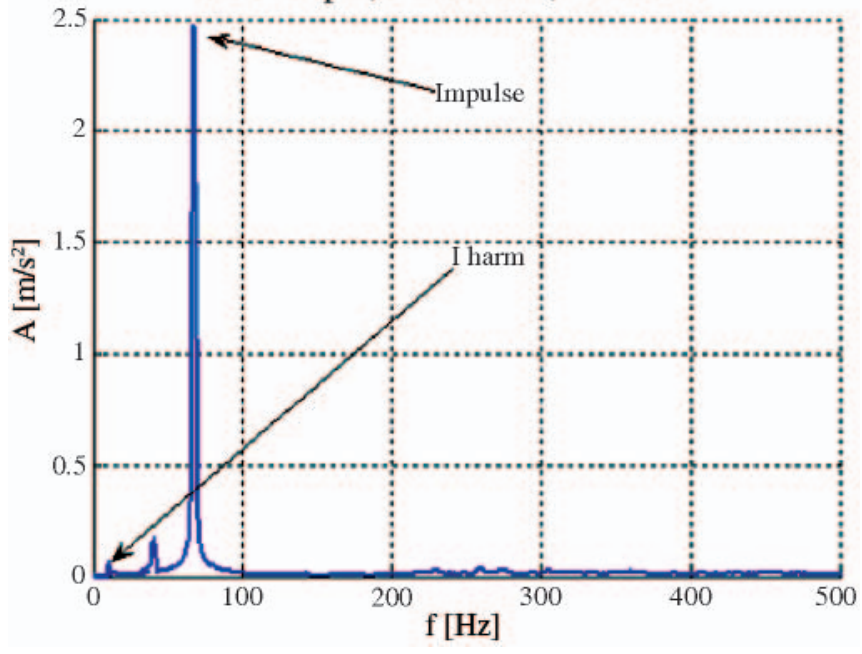

Fig. 5. Simulated transverse vibration spectrum at point 2 for $n_{P S}=375 \mathrm{rev} / \mathrm{min} \varangle \mathrm{K}=0^{\circ}, \varsigma=5 \mathrm{~m}$, and detonation pulse $i_{D}=50 \mathrm{~g}$

Fig. 6 shows the simulated action of the underwater detonation at point 1 of the propeller shaft model, done for two distances of the detonation epicentre from the ship hull. The transverse vibration spectra of the propeller shaft loaded with the underwater detonation pulse suggest the existence of a remarkable effect of the distance from the detonation epicentre on the vibration acceleration at the examined point. The nature of the pulse load makes use of the pulse load model [1,4].

In order to illustrate the sensitivity of the model to changes in shaft line misalignment, in Fig. 7 are shown selected spectra of vibration velocities which were recorded at point 2, along $\mathrm{V}$-axis, for course and wave amplitude parameters equal to $\varangle \mathrm{K}=0^{\circ}$ and $\varsigma=5 \mathrm{~m}$, respectively, and for the propeller shaft rotational speed $\mathrm{n}_{\mathrm{PS}}=570 \mathrm{rev} / \mathrm{min}$, for shaft axis displacements $\mathrm{P}=0.2 \mathrm{~mm}$ and $\mathrm{P}=0.5 \mathrm{~mm}$.

Acceleration spectrum of radial shafts vibration, eksplosion load from $\mathrm{R}=50 \mathrm{~m}$

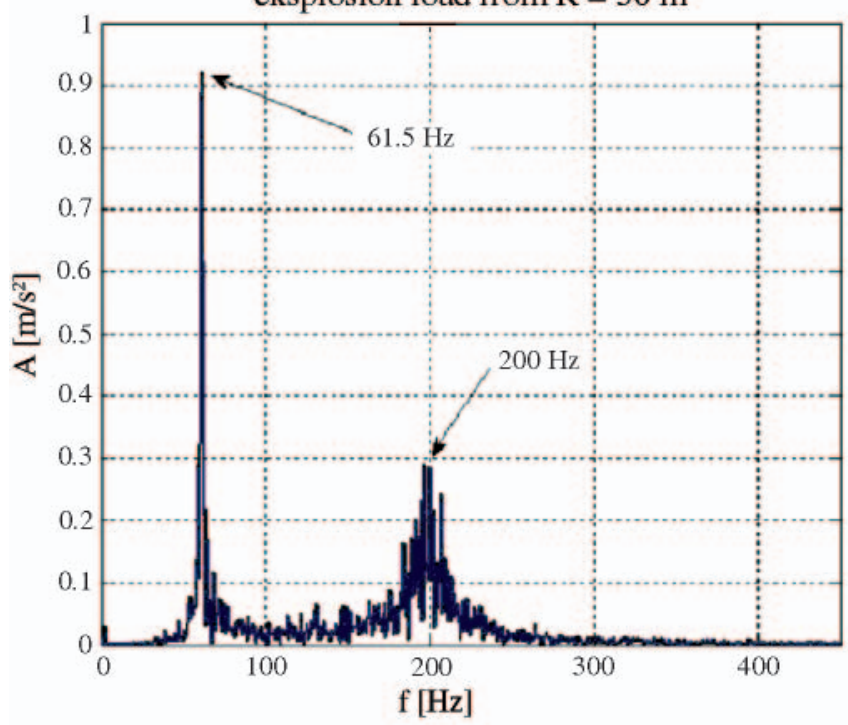

Acceleration spectrum of radial shafts vibration, eksplosion load from $\mathrm{R}=200 \mathrm{~m}$

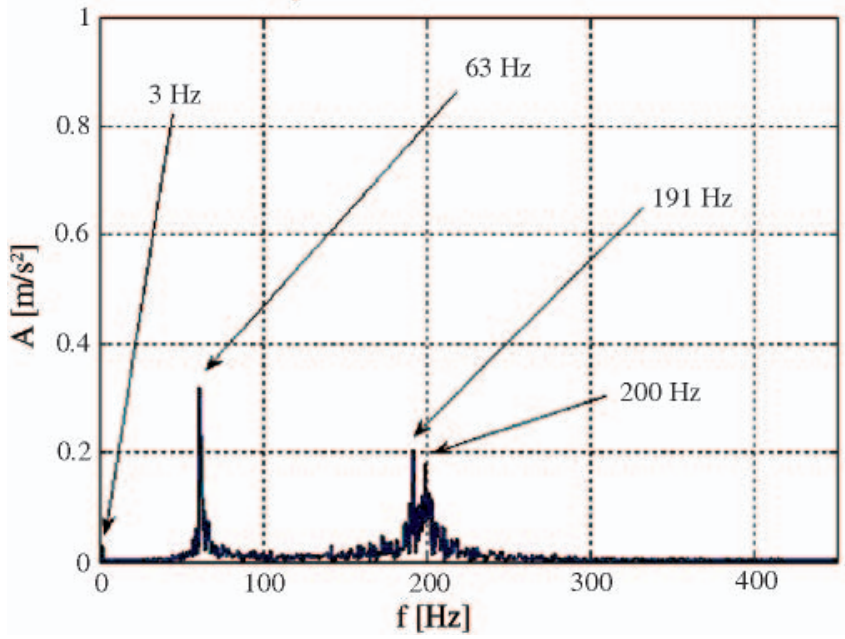

Fig. 6. Simulated transverse vibration acceleration spectra at point 1 for the charge mass $m=40 \mathrm{~kg}$ blowing at a distance $R=50 \mathrm{~m}$ and $R=200 \mathrm{~m}$

The obtained results confirm the unique effect of shaft axis displacements on the structure and characteristic parameters of the modelled spectrum.

\section{IDENTIFYING THE PROPELLER SHAFT MODEL}

The presented dynamic model of the propeller shaft was loaded with virtual loads, including coupled loads, in order to check model applicability to technical diagnostics purposes. The basic criterion for the model compliance with the real object is the compliance of corresponding spectra in frequency domain for different shaft revolutions in stationary conditions [3]. A sample analysis of the results of simulation is given in Figs. $8 \mathrm{a}$ and $8 \mathrm{~b}$. Changes in the shaft rotational speed which were assumed in the model have resulted in the increase of frequency of the basic harmonic and the sixth harmonic, being an identified symptom of shaft axis misalignment, like in the investigations of a real object. At the same time, the value of the symptom corresponding to the shaft axis displacement by $\mathrm{P}=0.1 \mathrm{~mm}$ increases with increasing shaft revolutions. 
a)

Spectrum of acceleration

Spectrum of velocity vibration $\mathrm{n}=570 \mathrm{rpm}$, $\mathrm{P}=0.2 \mathrm{~mm}, \mathrm{v}=20 \mathrm{Kn}$, wave $=5 \mathrm{~m}$
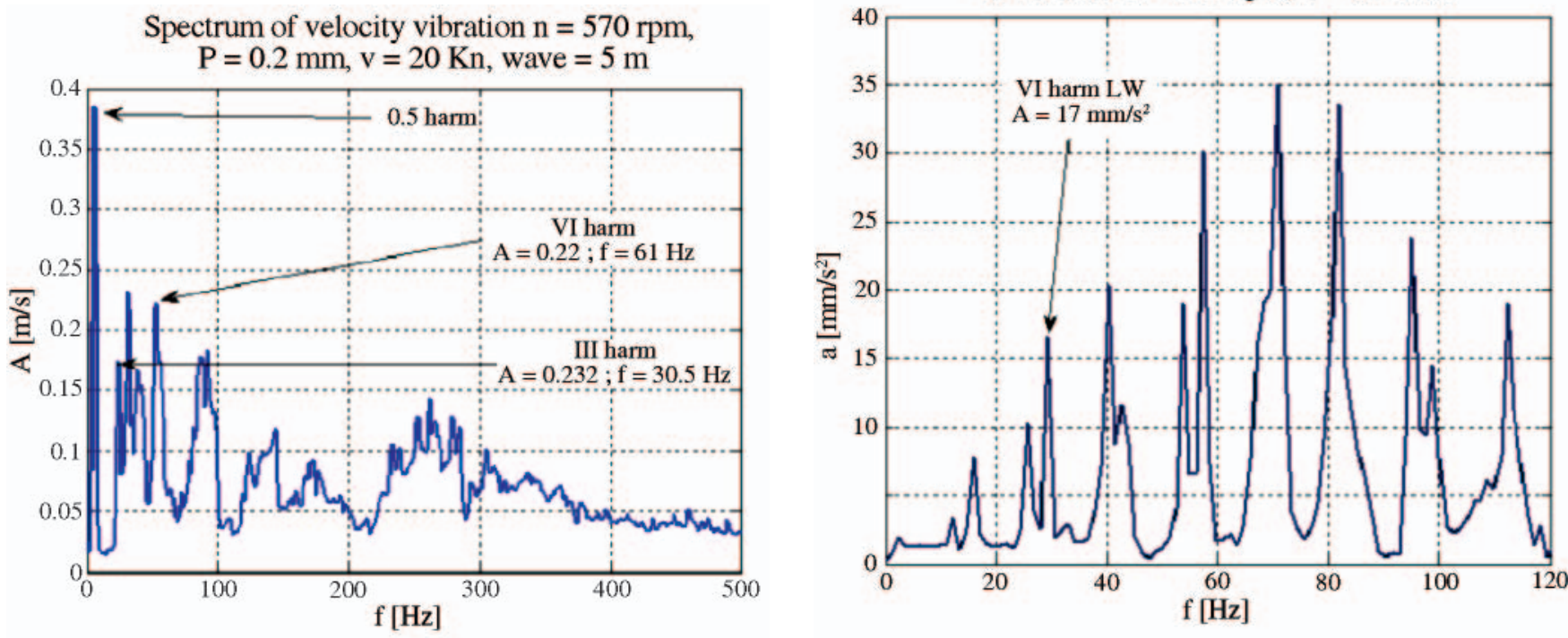

Spectrum of velocity vibration $\mathrm{n}=570 \mathrm{rpm}$,

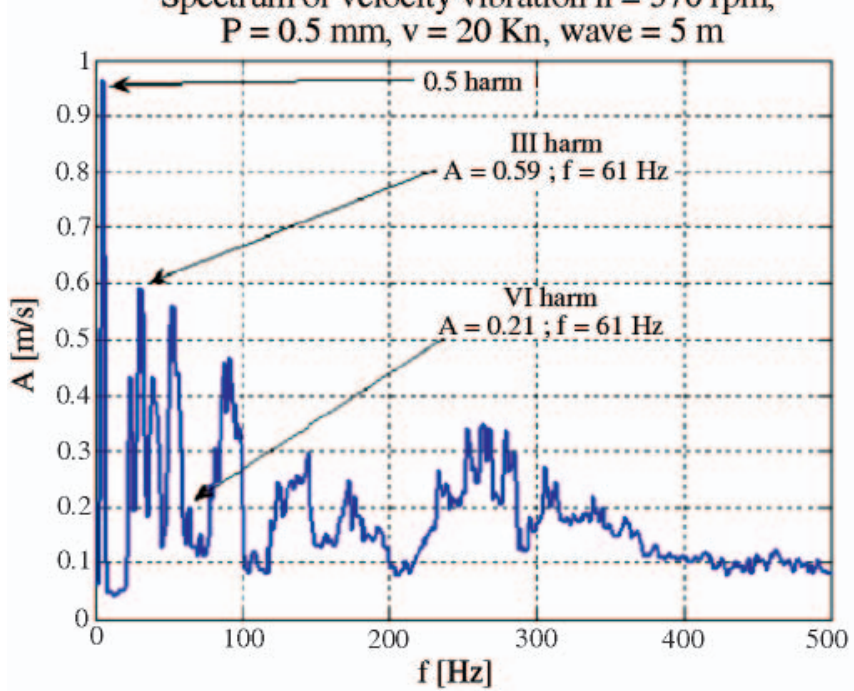

b)

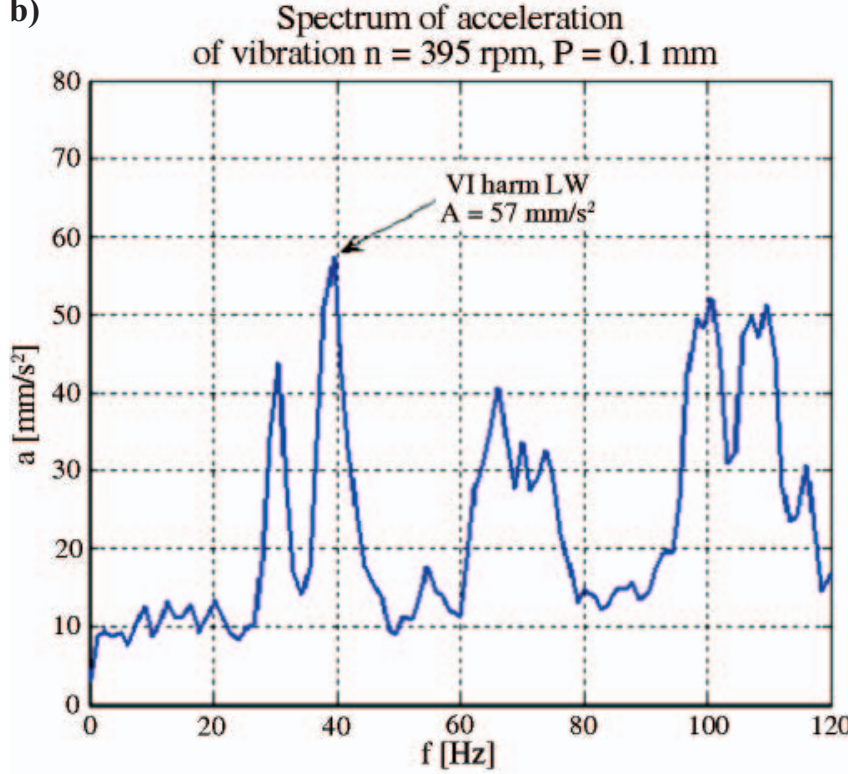

Fig. 7. Simulated transverse vibration velocity spectra at point 2 for assumed propeller shaft axis displacements equal to $P=0.2 \mathrm{~mm}$ and $P=0.5 \mathrm{~mm}$

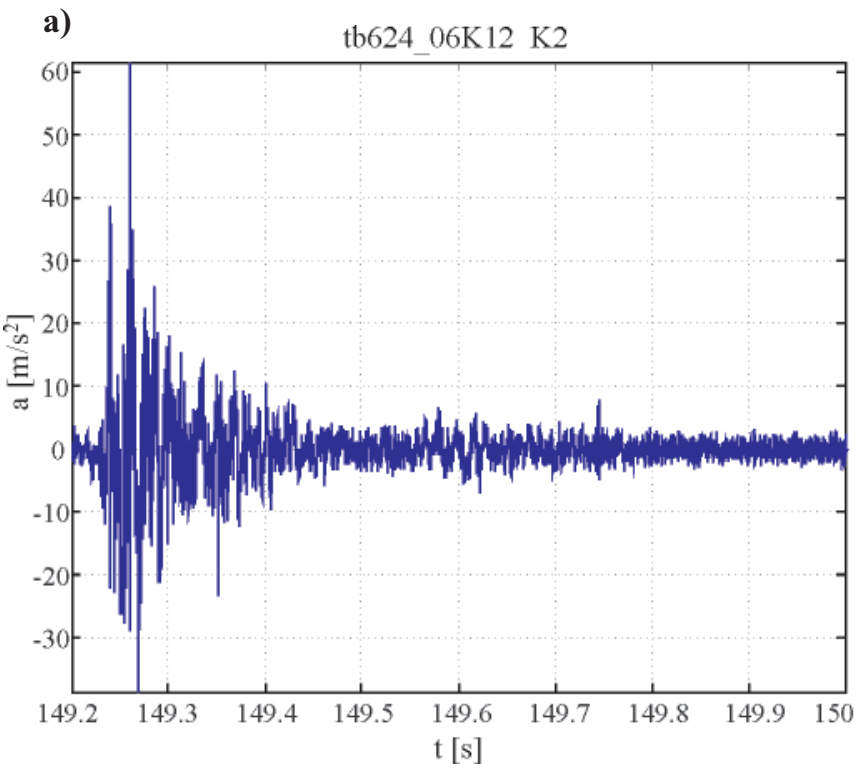

Fig. 8. a) simulated vibration acceleration spectrum for shaft revolutions $n_{P S}=295 \mathrm{rev} / \mathrm{min}$ at axis displacement $\left.P=0.1 \mathrm{~mm} ; \boldsymbol{b}\right)$ simulated vibration acceleration spectrum for shaft revolutions $n_{P S}=395 \mathrm{rev} / \mathrm{min}$ at axis displacement $P=0.1 \mathrm{~mm}$

b) Timewaveform of acceleration, bearing 2 ,

axis $\mathrm{V}, \mathrm{m}=40 \mathrm{~kg}, \mathrm{R}=400 \mathrm{~m}, \mathrm{~h}=32 \mathrm{~m}$

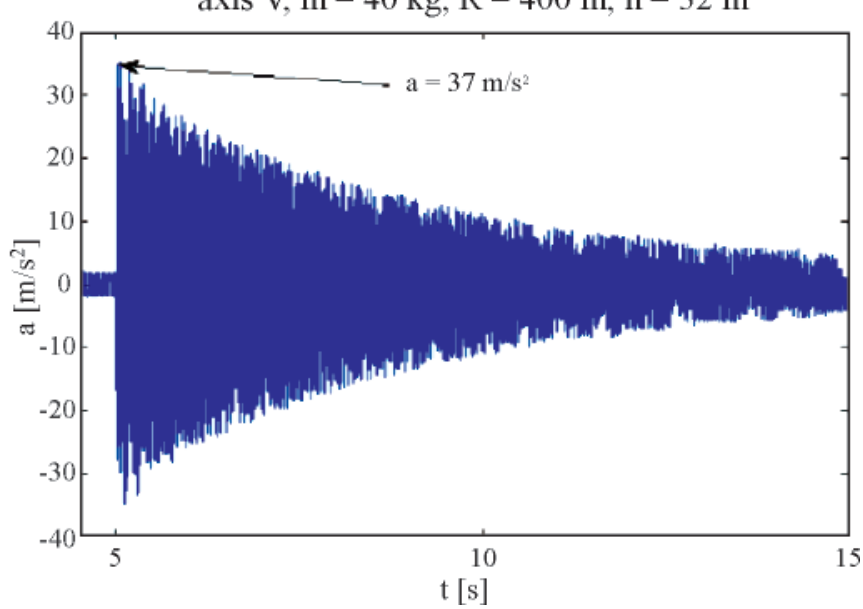

Fig. 9. a) real vibration acceleration time-history recorded during underwater detonation, b) simulated vibration acceleration time-history during underwater detonation 
The identification of elastic shaft deformations provoked by an underground detonation is shown in Figs. 9a and 9b. The results measured on a real object were obtained on the marine testing ground after detonating the TNT blowing charge of $\mathrm{m}=40 \mathrm{~kg}$ at a distance of $\mathrm{R}=400 \mathrm{~m}$ and the depth of $\mathrm{h}=32 \mathrm{~m}$ [4]. The simulated detonating action which was introduced to the model consisted of 3 successive pulses, according to the Cole relation [1]. The elastic deformation is best visible when comparing the time-histories of vibration accelerations. Like a real curve, the simulated vibration acceleration time-history is intensively damped, which testifies to the self-centring of the propeller shaft and the elastic nature of the deformation.

The next step in model identification consisted in comparing the results of simulations and measurements done on a real object for known shaft misalignment. The levels of the first and sixth vibration velocity harmonics recorded on the reduction gear thrust bearing casing (point 1 in the model) are given in Fig. 10a, while Fig. 10b shows the effect simulated for the assumed axis displacement equal to $\mathrm{P}=0.2 \mathrm{~mm}$, the same as on the real object.

a)

\section{Autospectrum channel A}

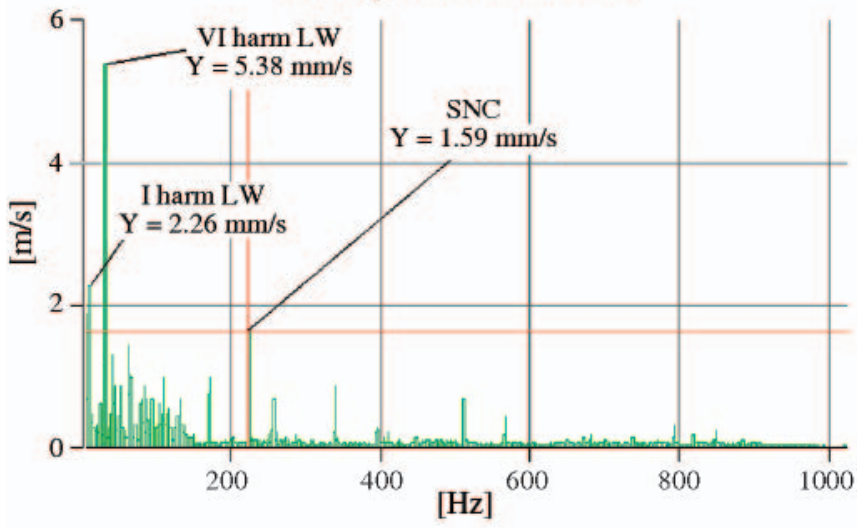

b) Spectrum of velocity of vibration $\mathrm{n}=300 \mathrm{rpm}$, $\mathrm{P}=0.2 \mathrm{~mm}$, waves A $5 \mathrm{~m}$

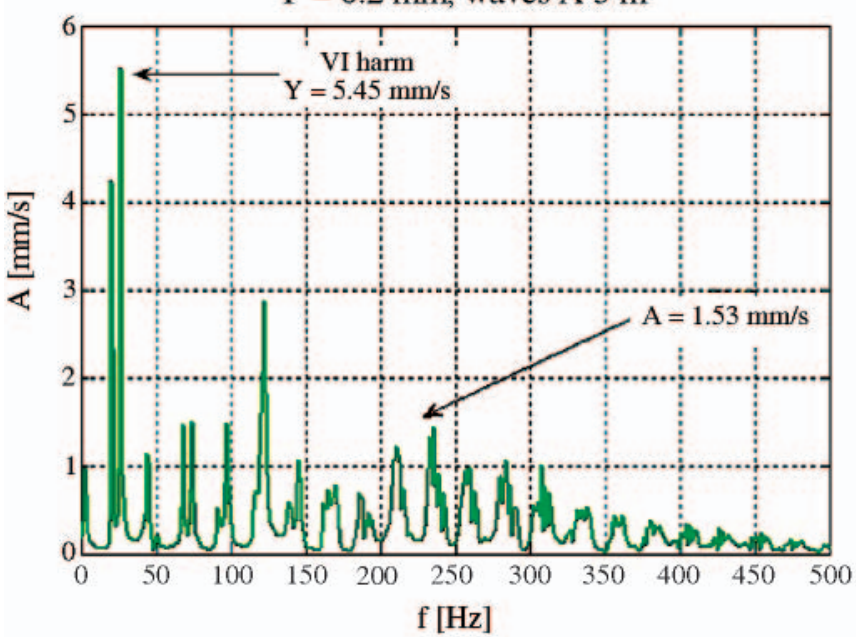

Fig. 10. a) vibration velocity spectrum measured on a real object; b) vibration velocity spectrum simulated using the proposed model

The analysis of the vibration velocity spectra shown in Figs. $10 \mathrm{a}$ and $10 \mathrm{~b}$ reveals that the model preserves similarity of the relations between the basic harmonics. Slight differences in the values of basic components result from the need to use a function which matches the effect of strong nonlinear damping of the water environment, in which a large part of the propeller shaft and the propeller screw are immersed. Identifying the mathematical model consists in such selection of a set of

coefficients or functions that the model solutions are close, within an assumed error tolerance, to the experimental results [8]. Table 2 collects maximum errors recorded when comparing model symptoms with those observed on the real object.

Tab. 2. Maximum errors of model symptoms with respect to the measured results

\begin{tabular}{|c|c|c|c|c|}
\hline Symptom & $\begin{array}{c}\text { Sixth } \\
\text { harmonic } \\
\text { of } \\
\text { vibration } \\
\text { velocity } \\
{[\mathbf{m m} / \mathbf{s}]}\end{array}$ & $\begin{array}{c}\text { Sixth } \\
\text { harmonic } \\
\text { of vibration } \\
\text { acceleration } \\
{\left[\mathbf{m m} / \mathbf{s}^{2}\right]}\end{array}$ & $\begin{array}{c}\text { Detonation } \\
\text { pulse } \\
{\left[\mathbf{m} / \mathbf{s}^{2}\right]}\end{array}$ & $\begin{array}{c}\text { First } \\
\text { harmonic } \\
\text { of } \\
\text { vibration } \\
\text { velocity } \\
{[\mathbf{m m} / \mathbf{s}]}\end{array}$ \\
\hline Measured & 12.4 & 5.38 & 212.2 & 8.97 \\
\hline $\begin{array}{c}\text { Obtained } \\
\text { from } \\
\text { model }\end{array}$ & 13.6 & 5.45 & 206.4 & 9.78 \\
\hline $\begin{array}{c}\text { Maximum } \\
\text { relative } \\
\text { error }\end{array}$ & $9.67 \%$ & $1.3 \%$ & $-2.73 \%$ & $9.03 \%$ \\
\hline
\end{tabular}

The maximum relative error was assumed not to exceed $10 \%$. Analysing the data collected in Tab. 2 leads to a conclusion that the proposed model is identifiable and sensitive to basic diagnostic parameters.

\section{CONCLUSIONS}

A basic goal of modelling is the identification of the diagnostic model. In the reported case, comparing the results of the empirical studies and the simulations has proved good applicability of the proposed model. The obtained results confirmed model sensitivity to changes of the technical state of the object and varying input parameters. A vital property of the model was the insensibility of the axis misalignment symptom to the action of assumed environmental disturbances, such as underwater detonation.

Comparing the measured results with those obtained from the simulations indicates that there is potential space for the use of the results of the simulations in the data base of the on-line monitoring system for propulsion systems used on mine countermeasure vessels. The proposed model is general in nature, which makes it possible to adapt it in similar propeller shaft constructions.

\section{NOMENCLATURE}

a

A

$\mathrm{c}_{\mathrm{Ig}} ; \mathrm{c}_{\mathrm{IIg}} ; \mathrm{c}_{\mathrm{IIIg}} ; \mathrm{c}_{\mathrm{IVg}}$

$\mathrm{c}_{\mathrm{Tg}} ; \mathrm{c}_{\mathrm{Ts}}$

$\mathrm{h}$

$\mathrm{h}_{\mathrm{SR} 1} ; \mathrm{v}_{\mathrm{SR} 1}$

$h_{\mathrm{N}} ; h_{\mathrm{I}} ; h_{\mathrm{II}} ; \mathrm{v}_{\mathrm{N}} ; \mathrm{v}_{\mathrm{I}} ; \mathrm{v}_{\mathrm{II}}-$ horizontal and vertical coordinates for masses $\mathrm{m}_{\mathrm{N}} ; \mathrm{m}_{\mathrm{I}} ; \mathrm{m}_{\mathrm{II}}$

$\mathrm{h}_{\mathrm{SR}} ; \mathrm{v}_{\mathrm{SR}} \quad-$ horizontal and vertical coordinate of the gravity centre $\mathrm{S}_{\mathrm{c}}$ (taking into account shaft deflection)

$\mathrm{i}_{\mathrm{D}} \quad-$ maximum detonation acceleration pulse

$\mathrm{I}_{\mathrm{N}} ; \mathrm{m}_{\mathrm{N}} \quad-$ reduced moment of inertia and reduced mass of the driving part

$\mathrm{I}_{\mathrm{SR}} ; \mathrm{m}_{\mathrm{SR}} \quad-$ reduced moment of inertia and reduced mass

of the driven part (screw)

- torsional stiffness of the propulsion system 


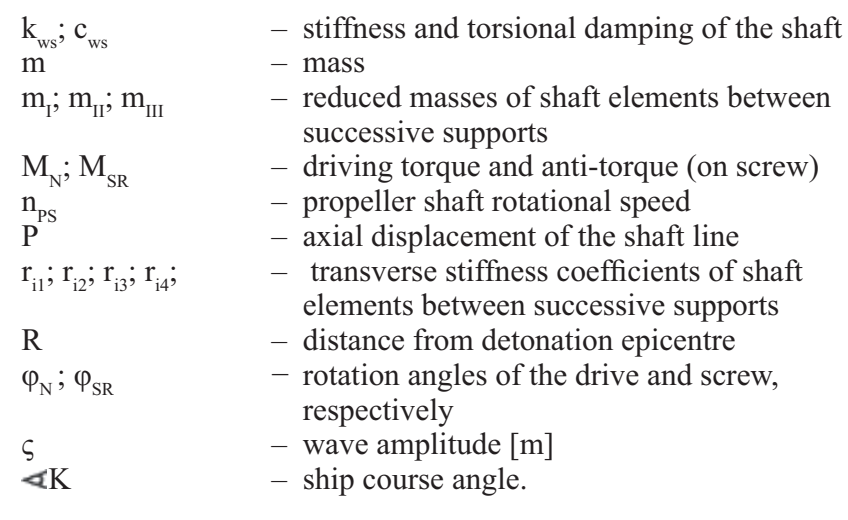

\section{BIBLIOGRAPHY}

1. Cole R. H.: Underwater Explosions. Princeton University Press, Princeton 1948
2. Cudny K.: Ship shafting. Structures and calculations (in Polish). Wydawnictwo Morskie. Gdańsk.1990

3. Dąbrowski Z.: Machine shafts (in Polish). PWN, Warszawa 1999

4. Grządziela A.: An analysis of possible assessment of hazards to ship shaft line, resulting from impulse load. Polish Maritime Research, No. 3/2007, pp. 14 - 17, Gdańsk 2007

5. Grządziela A.: Dynamic problems of shaftslines. Diagnostyka No. 4 vol. 44/ 2007 r, pp. 5 - 10, Olsztyn 2007.

\section{CONTACT WITH THE AUTHOR}

Andrzej Grządziela, Assoc. Prof.

Mechanic-Electric Faculty,

Polish Naval University

Śmidowicza 69

81-103 Gdynia, POLAND

e-mail : AGrza@amw.gdynia.pl

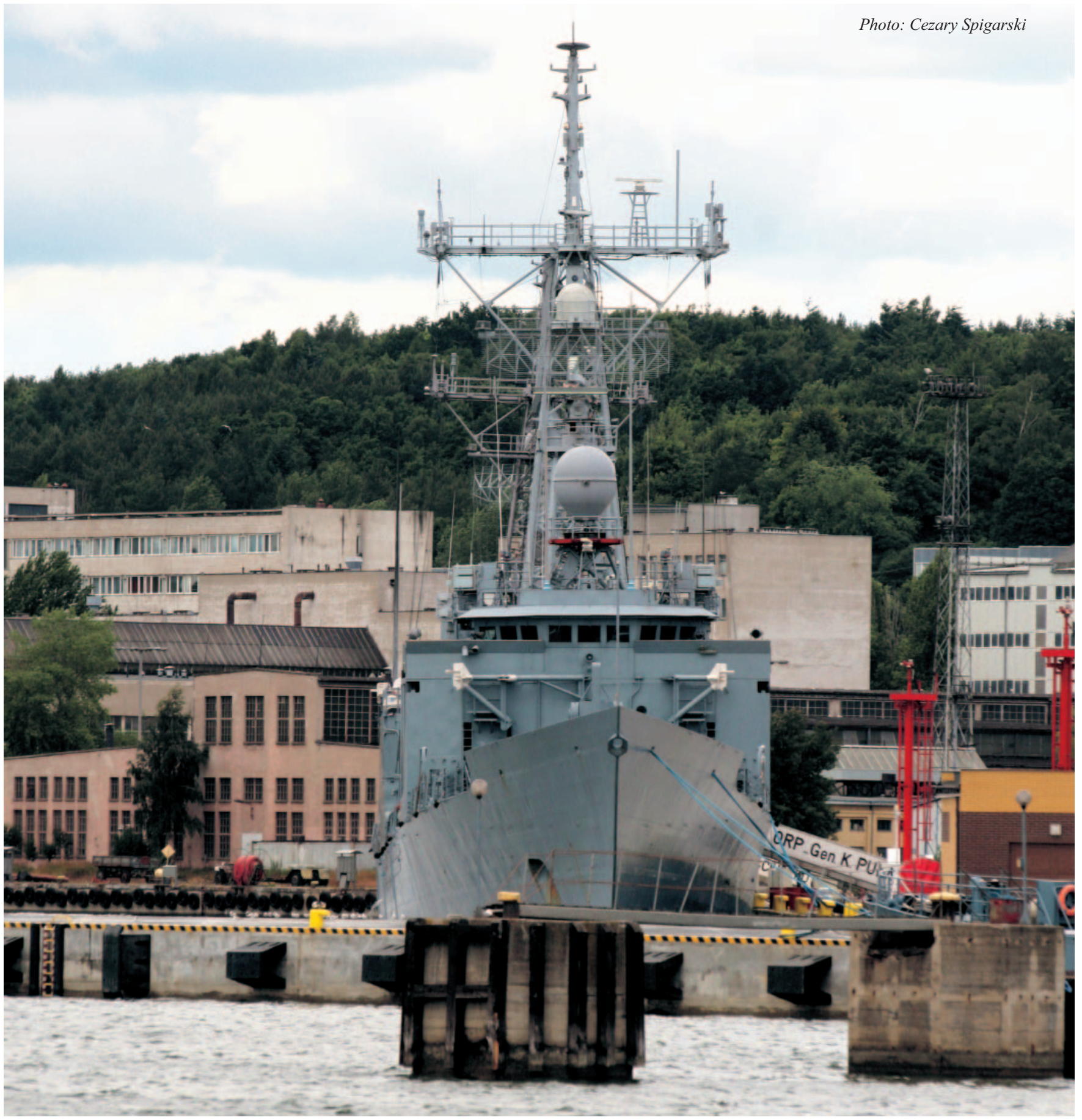

